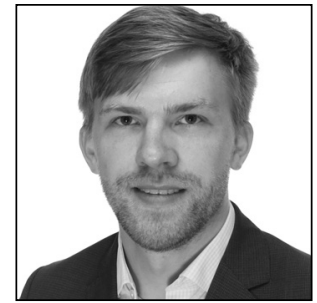

Märt Maarand

\title{
Bank Recovery and Resolution Measures' Restrictive Effects on Appealing Against Them
}

\section{Introduction}

With the Bank ${ }^{*_{1}}$ Recovery and Resolution Directive (BRRD) ${ }^{*_{2}}$, the framework for recovery and resolution for credit institutions was established in the euro area with date of transposition at the start of 2015. The recovery and resolution framework was envisaged as taking care of situations that supervision has failed to prevent, and, ironically, the greater the supervisory failure, the more successful the resolution may appear. ${ }^{*}{ }^{3}$ Within this new framework, new tools and powers were established for authorities involved both in bank recovery proceedings and in resolution proceedings ${ }^{*}$, which differ, whether extensively or to a lesser degree, from those within the pre-existing prudential supervision framework. While these new recovery and resolution frameworks may have noble, although competing, objectives ${ }^{*}{ }_{5}$ and have been argued to contribute to stabilising the EU financial system ${ }^{*}$, the specific protective actions a credit institution may take to defend itself from unlawful application of the new measures have not been harmonised on the EU level. Article 85 of the BRRD, in its sections 2 and 3, established the general rule that the member states must ensure that appeal procedures are in place for both crisis prevention measures ${ }^{*} 7$ and crisis management measures. At the same time, that article's Section 4 imposes significant restrictions on the appeal procedures - in essence, prohibiting interim relief and limiting the remedies for a wrongful decision or action on the part of the resolution authority to compensation for the losses suffered. Moreover, the nature and

1 While 'bank' and 'credit institution' may have different scopes of meaning, this has no effect in the context of the article. Therefore, 'bank' and 'credit institution' are used interchangeably.

2 Directive 2014/59/EU of the European Parliament and of the Council of 15 May 2014 establishing a framework for the recovery and resolution of credit institutions and investment firms [2014] OJ L173/190.

3 For a practical example, see Mikaella Yiatrou, "The Myth of Cypriot Bank Resolution "Success": A Plea for a More Holistic and Less Costly Supervision \& Resolution Approach' (2017) 18 European Business Organization Law Review 503, 504 and 530. - DOI: https://doi.org/10.1007/s40804-017-0080-4.

4 Pamela Lintner, 'De/centralized Decision Making under the European Resolution Framework: Does Meroni Hamper the Creation of a European Resolution Authority?' (2017) 18 European Business Organization Law Review 591, 592. - DOI: https://doi.org/10.1007/s40804-017-0082-2.

5 On competing objectives of the BRRD, see Edoardo Martino, 'The Bail-In beyond Unpredictability: Creditors' Incentives and Market Discipline' (2020) 21 European Business Organization Law Review 789, 791, 803, and 821. - DOI: https://doi. org/10.1007/s40804-020-00188-7.

6 On the stabilising effect of the BRRD, see Giovanni Covi and Ulrich Eydam, 'End of the Sovereign-Bank Doom Loop in the European Union? The Bank Recovery and Resolution Directive' (2020) 30 Journal of Evolutionary Economics 5. - DOI: https://doi.org/10.1007/s00191-018-0576-2.

7 This includes recovery measures - see the BRRD, art 2(1)(101). 
outcomes of these new measures themselves have profound material influence on the effectiveness of the credit institution's defensive actions. One key property of the measures is a restrictive effect on the credit institution's independent decision-making and on the management's loyalty toward the shareholders and the credit institution, which, in turn, exerts a negative influence on motivation to appeal against harmful unlawful administrative acts adopting the same measures. As there have been calls for expanding the single resolution regime to cover also non-bank participants in the financial sector ${ }^{*}$, these factors should be considered with regard to the whole financial sector.

This article concentrates on direct impacts that specific measures available to authorities in bank recovery and resolution proceedings have on the possibilities available to a bank for deciding to appeal against application of the measure in question. That is, might the result of respective specific administrative powers in either recovery or resolution proceedings make it impossible for a bank to defend itself from unlawful application of these powers? Objective legal justice - in the sense of mounting a challenge to unlawful measures targeted at an entity and claiming compensation for related damages - is presumed to be in the interest of the entity whose interests the management should pursue. While there are pragmatic or materialist reasons for which this path to defending oneself from an unlawful action may not always be followed in practice, such situations and influences are not covered by the scope of this article. Applying the presumption that eliminating the injustice, whether or not any material damage is involved, is considered the most beneficial action for the entity and, accordingly, the expected goal from the management's perspective.

The nature of the key issue of loyalty is addressed in the first chapter. Because recovery can be considered a distinguishable concept preceding resolution ${ }^{*}$, the effects of key measures taken in the bank's recovery are examined in the second chapter, before the effects of measures employed in bank resolution are addressed, in the third chapter. With this groundwork laid, the enforceability of the declared rights of appeal in the context examined can be assessed and conclusions stated.

\section{Interest in challenging unlawful administrative acts}

In normal circumstances, a credit institution operates its business as an independent entity with its individual units in the corporate structure each fulfilling the specific dedicated functions. Here, we regard the units and their members or participants to be responsible for running the credit institution and, hence, the ultimate decision-making authority. The EU legislation defines a credit institution's management body as the body or bodies appointed in accordance with national law that are empowered to dictate the institution's strategy, objectives, and overall direction and that oversee and monitor management decision-making, with inclusion of those persons who effectively direct the business of the institution. ${ }^{*}{ }^{10}$ With regard to overseeing and monitoring management decision-making, a management body is defined as the management body in its supervisory function ${ }^{* 11}$, and 'senior management' is considered to refer to those natural persons who exercise executive functions within the institution and who are responsible for, and accountable to the management body for, the day-to-day management of the institution. ${ }^{* 12}$ For the national dual-board systems traditionally prevailing in civil-law countries ${ }^{*} 3$, or separation of functions within a management body, the Member State must identify the responsible bodies or members. ${ }^{* 14}$ For example, in Estonia's dual-board

8 Danny Busch and Mirik BJ van Rijn, 'Towards Single Supervision and Resolution of Systemically Important Non-Bank Financial Institutions in the European Union' (2018) 19 European Business Organization Law Review 302. - DOI: https:// doi.org/10.1007/s40804-018-0107-5.

9 On recovery as a distinguishable concept, see Märt Maarand, 'The Concept of Recovery of Credit Institutions in the Bank Recovery and Resolution Directive' (2019) 28 Juridica International 103. - DOI: https://doi.org/10.12697/ji.2019.28.12.

10 Directive 2013/36/EU of the European Parliament and of the Council of 26 June 2013 on access to the activity of credit institutions and the prudential supervision of credit institutions and investment firms [2013] OJ L176/338 (CRD IV), art 3(1)(7).

11 CRD IV, art 3(1)(8).

12 CRD IV, art 3(1)(9).

13 Kathrin Johansen and others, 'Inside or Outside Control of Banks? Evidence from the Composition of Supervisory Boards' (2017) 43 European Journal of Law and Economics 31, 31-32. - DOI: https://doi.org/10.1007/s10657-014-9463-y; on mixed systems, see, for example, Caspar Rose, 'Board Composition and Corporate Governance - a Multivariate Analysis of Listed Danish Firms' (2006) 21 European Journal of Law and Economics 113, 114-115.- DOI: https://doi.org/10.1007/ s10657-006-6645-2.

14 CRD IV, art 3(2). 
system, the supervisory board has relatively broad planning, organisation, approval, and supervisory powers, also seeing to the election and removal of the management board's members, but does not have the capacity for external representation. ${ }^{*} 5$ In this context, the senior management, holding the mandate for external representation and appeals in the name of the bank, are in focus. It is important to point out also that the BRRD's focus is clearly on protecting the general stability of financial markets ${ }^{* 16}$ and that it does so, as is made evident in chapters 2 and 3 below, by harmonising those public administrative powers that may interfere with and override the management under company-related civil law.

For management bodies and the members thereof, there are harmonised minimum requirements that must be met if they are to qualify for the position, both as individuals and collectively. These are commonly referred to as the fit and proper requirements. ${ }^{*}{ }^{17}$ Specifically, the European Banking Authority (EBA) and the European Securities and Markets Authority (ESMA) have set out loyalty as a relevant skill for members of the management bodies in their joint guidelines addressed to both supervisory authorities and credit institutions. ${ }^{*} 18$ The EBA and ESMA have defined loyalty, in Annex II to the Joint Guidelines (under point h), as identifying with the undertaking and having a sense of involvement; showing that one can devote sufficient time to the job and can discharge his or her duties properly, defending the interests of the undertaking and operating objectively and critically; and recognising and anticipating potential conflicts of personal and business interest. Moreover, paragraph 82(b) of the Joint Guidelines sets out as an aspect of the independence of mind, that the members of the management body must not have conflicts of interest to an extent as would impede their ability to perform their duties independently and objectively. Sources of conflicts of interest have been further detailed, in paragraph 84 of the same guidelines, as encompassing at least economic interests, a relationship with holders of qualified holdings, personal and professional relationships with the staff, other current or previous employment of a relevant sort, personal and professional relationships with relevant external stakeholders, memberships in body or ownership of a body or entity with interests that are in conflict with those of the entity in question, and political influence or political relationships. Within the context of this article, the elements of loyalty specified here may be infringed by the measures taken within the bank recovery or resolution frameworks, and, more precisely, conflicts of interest may arise between a manager's personal interest in the unlawful administrative act remaining in effect and the presumed interest of the credit institution in appealing against said act. Acting counter to the bank's interest in appealing an unlawful recovery or resolution act while the outcomes stemming from the relevant act may be beneficial for the manager's personal interests would demonstrate the manager to be clearly unfit for the position.

According to paragraph 85 of the Joint Guidelines, all actual and potential conflicts of interest at management-body level should be adequately communicated, discussed, documented, decided on, and duly managed by the management body (i.e. the necessary mitigating measures should be taken), and a member of the management body should abstain from voting on any matter with regard to which that member has a conflict of interest. However, the first conflict of interest follows from the regulations themselves, according to which managers' conflicts of interest must be managed primarily by the managers and management bodies themselves. ${ }^{* 19}$ They are usually, in turn, supervised by the authority adopting the measures, which may have created the conflict of interest in the first place. ${ }^{* 20}$ Moreover, the existence of a conflict of interest

15 Äriseadustik, RT I 1995, 26, 355, § 309(1) and § 316-317; on differences of boards in Estonian legal theory, see Andres Vutt and Margit Vutt, 'Duties and Liability of the Members of the Supervisory Board of Limited Companies in Estonia: The First Cases from the Supreme Court of Estonia' (2017) 26 Juridica International 66. - DOI: https://doi.org/10.12697/ ji.2017.26.07.

16 Financial stability is mentioned in the recitals of the BRRD at least 42 times. For references to the objectives more specifically, see the BRRD, art 3(7), plus recitals 3-8, 18, 29, and 40; Commission, 'Impact Assessment Accompanying the Document Proposal for a Directive of the European Parliament and of the Council Establishing a Framework for the Recovery and Resolution of Credit Institutions and Investment Firms' SWD (2012) 166 final 4, 19-21 (Impact Assessment).

17 European Securities and Markets Authority, European Banking Authority, 'Joint ESMA and EBA Guidelines on the assessment of the suitability of members of the management body' EBA/GL/2017/12 (26 September 2017) (Joint Guidelines); European Banking Authority, 'Guidelines on Internal Governance’ EBA/GL/2017/11 (21 March 2018); European Central Bank, 'Guide to Fit and Proper Assessments' (May 2018).

18 Joint Guidelines, para 61 and Annex II(h).

19 CRD IV, art 88; European Banking Authority, 'EBA Guidelines on Internal Governance’ EBA/GL/2017/11 (21 March 2018), paras 23(l) and 33(g), Sections 11, 12, and 16.

20 Prudential supervision, recovery, and resolution, may, de facto, be all conducted by the same authority on national level BRRD, recital 15, art 2(1)(21), 3(1) and 3(3); Regulation (EU) No 575/2013 of the European Parliament and of the Council of 26 June 2013 on prudential requirements for credit institutions and investment firms [2013] OJ L176/338 (CRR), art $4(1)(40)$. 
is indisputable if any of the measures at issue should have the material effect of removing the managers or transferring management powers to the supervisory or resolution authority - for complete fulfilment of the proper management functions, that authority should then challenge its own act. Thus, material effects of bank recovery and resolution measures on the independent and loyal decision-making connected with challenging these measures can arise from two aspects of the situation: conflict of interest at the level of individual managers and conflict of interest arising from the authority itself taking over the management functions.

\section{Effects of measures in bank recovery}

\subsection{Recovery planning and early intervention measures}

As stated above, the concept of bank recovery can be distinguished from the prudential framework and the concept of resolution. More specifically, the function of bank recovery occupies a space between the framework, on the one hand, and the resolution framework, on the other, and is made up of three integral components - recovery planning, early intervention measures, and two additional measures targeted directly at the bank's management bodies. ${ }^{* 21}$ The same competent authority that is responsible for the prudential supervision is responsible also for taking measures within the recovery framework. ${ }^{* 22}$ This part of the article is devoted to recovery planning and early intervention measures, while the next subchapter addresses the additional measures.

The first component of the recovery framework, the recovery planning, leaves the responsibility primarily with the credit institution - it must devise and maintain a recovery plan in line with certain principles ${ }^{*} 23$ to address a hypothetical crisis scenario in a hypothetical manner. ${ }^{* 24}$ The recovery plans are ex ante plans of steps for later implementation, which may bring in difficulties of its own. ${ }^{*} 25$ The competent authorities lack legal capacity to change the recovery plans directly but can address deficiencies in recovery planning by applying indirect measures targeted at recovery plans, the entity's risk profile, its funding, or governance. ${ }^{*} 6$ These measures do not entail any significant conflict for the managers or give direct managerial powers to the competent authorities. No negative effects on challenging such measures are present in the current context.

The second integral component of the recovery framework is the early intervention measures. According to the Impact Assessment of the BRRD, the early intervention mechanism was designed for the competent authorities' use for obliging banks to undertake certain measures to avert major problems while leaving the control of the institution in the hands of its management. ${ }^{* 27}$ This provides assurance that at least the objective was not to give the competent authority any direct managerial powers. Also, the EBA has issued guidelines delimiting the triggers for applying early intervention measures. ${ }^{*} 28$ However, effects on managers' personal loyalty are still possible. With the novelty of the recovery measures having been examined previously ${ }^{* 29}$, the next step is to identify and assess the effects of early intervention measures on conflicts of interest with specific regard to appealing against the adoption of these measures.

Article 27(1)(a) of the BRRD lays out the first early intervention measure, a recovery-specific measure that can be summarised as requiring an institution to activate parts of the recovery plan or to update the plan. According to Article 5(1) of the BRRD, the main objective for recovery plans is to restore the entity's financial position following a significant deterioration of its financial situation. Annex A to the BRRD lists the set of 20 elements that a recovery plan must include at minimum. Of these elements, only the one that entails activating arrangements and measures to restructure business lines may be seen as potentially tied in

21 Maarand (n 9) 110.

22 Ibid 106.

23 For these core principles, see ibid 106-107.

24 Sven Schelo, Bank Recovery and Resolution (2nd edn, Kluwer 2020) s 3.01.

25 Costanza A Russo, 'Resolution Plans and Resolution Strategies: Do They Make G-SIBs Resolvable and Avoid Ring Fence?' (2019) 20 European Business Organization Law Review 736, 738. - DOI: https://doi.org/10.1007/s40804-018-0127-1.

26 BRRD, arts 5 and 6; Maarand (n 9) 108.

27 Impact Assessment, 83.

28 European Banking Authority, 'Guidelines on Triggers for Use of Early Intervention Measures Pursuant to Article 27(4) of Directive 2014/59/EU' EBA/GL/2015/03 (29 July 2015).

29 Reference from here on regarding the novelty of the early intervention measures involved is based on Maarand (n 9). 
with some personal interests of managers. When one takes into account the division of responsibilities and individual managers' accountability in the banking industry ${ }^{*} 30$, each manager could be seen as potentially interested in the benefits that unlawful activation of the recovery plan might bring to divisions under his or her responsibility, relative to other divisions. Two other early intervention measures have similar potential effects: requiring changes to the business strategy (covered in Article 27(1)(f) of the BRRD) and requiring changes to the legal or operational structures (covered in Article 27(1)(g) of the BRRD). While a negative effect on motivation to appeal on the part of managers responsible for business benefits may theoretically exist, the other managers may be considered equally motivated to challenge the activation of such arrangements, if not more so. Therefore, the theoretical negative impact may be regarded as limited in extent.

Under Article 27(1)(b) of the BRRD, the competent authority may require the management body of the institution to examine the situation, identify measures to overcome any problems, and draw up an action programme and a timetable for its implementation. Resembling the prudential power to require a plan to restore compliance with prudential requirements ${ }^{*}{ }^{31}$, it can be inferred that neither does the outcome entail any significant novel impact on a manager's personal interests nor does the competent authority take over the management duties. The power to require the management body to draw up a plan for negotiation on restructuring of debt in accordance with the recovery plan, established via Article 27(1)(e) of the BRRD, and the power to require information, established under Article 27(1)(h) of the BRRD, can be seen also as purely burden-creating requirements that, in essence, do not impose any significant conflicts of interest with regard to the decision to appeal.

The next early intervention measure, set out in Article 27(1)(c) of the BRRD, enables the competent authority to require the bank's management body to convene or, if the management body fails to comply with the imposition of that requirement, directly convene a meeting of shareholders, set the agenda for this, and require certain decisions to be considered for adoption. The main focus in creating this power seems to have been on increasing capital in emergency situations. ${ }^{*}{ }^{32}$ As seen, the competent authority's powers are layered by intensity of intervention - imposing an obligation is the first stage, and taking over specific direct powers from the management is the second one. The first stage may bring limited effects on individual managers that are similar to those of the first intervention measure discussed above. The second step, however, involves usurping the management body's functions and directly exercising its powers. This is not in accordance with the initial objective of obliging banks to act while leaving the control in the hands of the bank's management, so the core of the concept differs from that for the first step and the other measures covered thus far. Yet, in that the managers are not removed from their positions or stripped of their powers by this measure alone, the presumed effects on appealing can be considered identical to the first step's. While the effects are limited to individual managers who might benefit, every manager and the management body as a whole retain their capacity to appeal against adoption of the measure in question.

The final early intervention measure - to require one or more members of the management body or the senior management to be removed or replaced if found unfit to perform the corresponding duties as established under Article 27(1)(d) of the BRRD - is similar to the power, covered by Article 16(2)(m) of the SSM Regulation ${ }^{*} 33$, of, at any time, removing people from the management bodies when they do not fulfil the fit and proper requirements. Although the objective is the same, the language of the article and that of the proposal for the SSM Regulation ${ }^{*} 34$ indicate that in the prudential framework the authority should be able to directly remove the managers, while the BRRD implies, especially in contrast against the similar resolution power ${ }^{*} 35$, placing this obligation on the credit institution, which should itself decide on the removal to comply with the obligation. This interpretation is further supported by Recital 39 of the BRRD, according to which shareholders should retain full responsibility for the institution and control of it throughout the recovery and early intervention phases, except when a temporary administrator has been appointed by the competent authority,

30 Paul Davies and Klaus J Hopt, 'Non-Shareholder Voice in Bank Governance: Board Composition, Performance and Liability' (2018) No 413 ECGI Working Paper Series in Law, 7-8. - DOI: https://doi.org/10.2139/ssrn.3226244.

31 CRD IV, art 104(1)(c); SSM Regulation, art 16(2)(c).

32 Impact Assessment, 36-37, 79, 209 and 238.

33 Council Regulation (EU) No 1024/2013 of 15 October 2013 conferring specific tasks on the European Central Bank concerning policies relating to the prudential supervision of credit institutions [2013] OJ L287/63.

34 Commission, 'Proposal for a Council Regulation Conferring Specific Tasks on the European Central Bank Concerning Policies Relating to the Prudential Supervision of Credit Institutions' COM (2012) 511 final, 5.

35 Cf BRRD, art 63(1)(l), per which 'the resolution authorities shall have the following resolution powers: the power to remove or replace the management body and senior management of an institution under resolution'. 
and under which they should no longer retain such responsibility once the institution has been put under resolution. The managers shall stay in their positions until the obligation to remove them has been fulfilled. This means that the credit institution retains its decision-making power to challenge such a measure and appeal against it. Moreover, the institution's decision-making bodies can and should act as a filter between the competent authority's goal of removing the manager and the end result, which should block unjustified demands from the competent authority by appealing and not complying with them. Since execution may not be compelled by the institution when the relevant prudential supervisory power is exercised, the approach within the recovery framework is far less intrusive than the approach in the prudential framework - surprisingly so.

In conclusion, the recovery planning and early intervention measures, if transposed correctly by the member states, should not give the competent authorities any new powers that create a direct consequence of rendering appeals impossible. Although some measures may have an indirect effect on motivation to appeal, the effect in this regard is limited. If these measures do not produce satisfactory results, the additional recovery measures may come into play. Then, the results might be very different.

\subsection{Additional recovery measures}

The recovery framework includes two additional measures available to competent authorities. With the first of these, Article 28 of the BRRD provides for another basis for removing managers: the competent authority may, if the measures considered in the previous subchapter prove insufficient to reverse the deterioration of the institution, require the removal of the senior managers or the entire management body. Interestingly, the initial proposal for the BRRD ${ }^{*} 36$ did not include this power but it does give additional freedom to the competent authority by citing the deterioration of the credit institution as the only precondition. The main difference from the similar early intervention measure addressed above is the absence of the prerequisite of the member or management body being unfit for the duties. Here, no deviation from the principle of obliging the institution to make the relevant decision can be detected; therefore, the managers should remain in place as representatives of the bank who may appeal against such action. However, there is no guarantee of the member states acknowledging the distinction of obliging the entity to act vs. applying direct power. For example, the Estonian legislation seems to fail to make this distinction, seemingly giving the competent authority direct power to remove managers itself as the mechanism of early intervention. ${ }^{*} 37$ Where national laws do not follow the principle of the institution retaining control and, instead, grant the state's competent authority the power to dismiss managers directly, as the Estonian case seems to exemplify, unlawful application of the measure that involves removing the management in its entirety would leave the bank without any representatives who could appeal against the unlawful removal of the managers. Thus, the bank may be unlawfully stripped of the representation by which it could and should appeal against the same unlawful removal; meaning the conventional mechanism by which the measure may be challenged by management bodies becomes inadequate. It may be argued also that removing some of the managers could leave the remaining managers acquiescent to the competent authority's actions for fear of losing their own position. A highly negative impact on the remaining managers' motivation to appeal seems obvious in this case.

The second additional measure, set out in Article 29 of the BRRD, takes things a step further - if the requirement to remove some or all of the managers is deemed to be insufficient for remedying the situation, competent authorities may appoint one or more temporary administrators for the institution. Paragraphs 1 to 4 of this article specify that appointing and removing a temporary administrator must be exclusive powers of the competent authorities; that, subject to the competent authority's discretion, a temporary administrator may either replace the management body of the institution temporarily or work on a temporary basis alongside the management body of the institution; and that said powers may include some or all of the powers of the management body of the institution as specified in the institution's statutes and under national law, among them the power to exercise some or all of the administrative functions of the management body of the institution. Regarding this measure, the initial proposal for the BRRD encompassed only replacement

36 Commission, 'Proposal for a Directive of the European Parliament and of the Council Establishing a Framework for the Recovery and Resolution of Credit Institutions and Investment Firms and Amending Council Directives 77/91/EEC and 82/891/EC, Directives 2001/24/EC, 2002/47/EC, 2004/25/EC, 2005/56/EC, 2007/36/EC and 2011/35/EC and Regulation (EU) No 1093/2010' COM (2012) 280 final (proposal for the BRRD).

37 Finantskriisi ennetamise ja lahendamise seadus, RT I, 19.03.2015, 3, 52, § 36(7). 
of the management ${ }^{*}{ }^{3}$, and the Impact Assessment refers that the nomination of such a person would in most cases mean the removal of the existing managers. ${ }^{*}{ }^{39}$ This indicates that replacement was regarded as the default option, while the added possibility of the management retaining some powers may create further options in some situations. It is obvious that a temporary administrator, presumably having consented to hold the position, has no motivation to appeal against the act that put him or her in that position and, in fact, finds the arrangement favourable personally. It can be presumed that the temporary administrator has an interest in keeping the act in force and retaining the position, regardless of unlawfulness. Hence, if the management is entirely replaced, again the logic whereby the institution's representatives are responsible for appeals fails to work - there is an interest exactly opposite that of countering unlawfulness.

The foregoing analysis of the provisions shows it to be possible for managers to be nominally left in place while the power of representation is stripped from them and conferred on a temporary administrator, with the same detriment to appeals. Interestingly, Article 29(8) of the BRRD provides that, subject to the preceding Article 28, the appointment of a temporary administrator shall not prejudice the rights of the shareholders in accordance with Union or national company law. Recital 40 of the BRRD implies, further, that the appointment of a temporary administrator should not unduly interfere with rights of the shareholders or owners or procedural obligations established under Union or national company law. The Impact Assessment even implies that the temporary administrator should act in accordance with the decisions of the general meeting of shareholders. ${ }^{*}{ }^{40}$ As the main way shareholders can usually influence their institution to appeal against an act is by appointing managers to do so and in that the relevant powers have been conferred on a temporary administrator, the opportunity to enforce such guarantees seems to be limited from the shareholders' perspective. Also, with the possibilities that the BRRD provides for limiting the temporary administrator's powers, per Articles 29(1) to 29(3); for subjecting temporary administrators' acts to prior consent by competent authorities per Article 29(5); and the right to remove a temporary administrator at any time and for any reason per Article 29(4), the competent authority possesses full control of the bank managers' and the temporary administrator's powers and actions - including actions against its acts. While the Impact Assessment characterises the appointment of such a temporary manager as an intrusive though efficient measure that should be applied only in exceptional cases ${ }^{*}{ }^{41}$, the fact remains that the target credit institution is stripped of any capacity to fight back against unlawful application of such power.

Analysis reveals that the additional recovery measures provided for may have a substantially different outcome than the measures that may be applied in recovery planning and early intervention. The bank's right of appeal may become only declarative since the very application of power at issue may remove the capacity to appeal. The concerns expressed by industry players about such measures in the early intervention stage ${ }^{*} 42$ seem to be well founded.

\section{Effects of key measures in bank resolution}

While the recovery framework extends the powers of competent authorities compared to the extensive preexisting prudential framework, the concept of uniform resolution procedure with resolution powers and resolution authorities was created only with the BRRD, which is accompanied by the Single Resolution Mechanism (SRM) Regulation. ${ }^{*} 43$ While during the recovery phase the control should stay in the hands of the credit institution's management, the approach taken in resolution is the opposite - the authorities take over the decision-making, with far-reaching resolution measures. ${ }^{* 44}$ By their very nature, the resolution actions created with the BRRD and the SRM Regulation bring infringements of rights of shareholders and

38 Proposal for the BRRD, 10-11 and 67.

39 Impact Assessment, 35.

40 Ibid. Note that the term used for the temporary administrator in the proposal for the BRRD and the Impact Assessment is inconsistent with the final text of the BRRD - the term initially used was 'special manager' - a term later transferred to a resolution measure of art 35 of the BRRD.

41 Ibid 36.

42 Ibid 222-223.

43 Regulation (EU) No 806/2014 of the European Parliament and of the Council of 15 July 2014 establishing uniform rules and a uniform procedure for the resolution of credit institutions and certain investment firms in the framework of a Single Resolution Mechanism and a Single Resolution Fund [2014] OJ L225/1.

44 BRRD, recital 39; Impact Assessment, 83; Maarand (n 9) 108. 
creditors. ${ }^{*} 45$ The BRRD includes a vast set of central powers, along with preparatory and ancillary supportive powers linked to bank resolution, from which resolution authorities can choose at their discretion in line with the resolution strategy devised for the individual institution. ${ }^{*} 6$ This chapter's scope is limited to key resolution measures available to resolution authorities in connection with resolution proceedings. These are related to general-application resolution tools, general resolution powers, special management, and persons exercising resolution powers.

\subsection{General resolution tools}

Under the BRRD's Article 37(3), four resolution tools make up the umbrella for resolution powers: sale of business, a bridge institution, asset separation, and bail-in. The sale of business tool involves the resolution authority's power of forced sale of the institution's shares (or other instruments of ownership) or all or any assets, rights, or liabilities to a third party while leaving the benefits to the owners of the shares or other instruments of ownership and to the institution. ${ }^{*} 47$ The bridge institution tool is similar in essence, but the ownership is transferred to a "bridge institution" ${ }^{\text {"* }}$, which is according to Article 4O(2) of the BRRD defines as a special dedicated legal person wholly or partially owned by public authorities and controlled by the resolution authority. The asset separation tool, in turn, is the power of forcibly transferring the institution's assets, rights, or liabilities to one or more asset-management vehicles ${ }^{*} 49$, which, is according to Article 42(2) of the BRRD likewise a special dedicated legal person owned wholly or partially by public authorities and controlled by the resolution authority. The main difference between these three tools from the bank's point of view involves the receiver - respectively, an independent third party, a bank under the resolution authority's control, or an asset management vehicle under resolution authority's control. According to Article 2(1) (57) of the BRRD, the bail-in tool is a mechanism for effecting a resolution authority's exercise of writedown and conversion powers in relation to liabilities of an institution under resolution in accordance with Article 43 of the BRRD. Hence, the bail-in tool is fundamentally different from the other resolution tools in its inclusion of direct losses, which, according to Article 44(9)(a) should be borne firstly by shareholders and then by creditors of the institution in order of preference. It is interesting that, while the credibility of the bail-in tool in particular has been identified as essential for banks' optimal debt structure and for ruling out extreme leverage ${ }^{*}{ }^{50}$, it has also been criticised as too complex to work in reality. ${ }^{*}{ }^{11}$ None of the resolution tools in general, per se, directly exerts negative effects with regard to the interests of members of the management bodies in appealing the application of the tool. Indirect impact connected with an individual manager's responsibilities is not out of the question, but the effect of such an impact on appealing the application of a resolution tool is limited similarly to the impacts accompanying early intervention measures.

\subsection{General resolution powers}

General resolution powers have been granted to the resolution authorities for purposes of application of the resolution tools ${ }^{*} 52$ in such a manner that resolution authorities will have powers to take control of an institution that has failed or is about to fail, take over the role of shareholders and managers, transfer assets and liabilities, and enforce contracts. ${ }^{*} 53$ According to Article 63(2) of the BRRD, the general resolution powers

45 Jens-Hinrich Binder, 'Proportionality at the Resolution Stage: Calibration of Resolution Measures and the Public Interest Test' (2020) 21 European Business Organization Law Review 453. - DOI: https://doi.org/10.1007/s40804-019-00143-1.

46 Tobias H Tröger, 'Too Complex to Work: A Critical Assessment of the Bail-In Tool Under the European Bank Recovery and Resolution Regime' (2018) 4 Journal of Financial Regulation 35, 19. - DOI: https://doi.org/10.1093/jfr/fjy002.

47 BRRD, art 2(1)(58), 38 and 39.

48 BRRD, art 2(1)(60) and 40.

49 BRRD, art 2(1)(60) and 42.

50 On the bail-in tool's effect on a bank's debt structure and leverage, see Luca Leanza and others, 'Bail-In vs Bail-Out: Bank Resolution and Liability Structure' (2021) 73 International Review of Financial Analysis. - DOI: https://doi.org/10.1016/j. irfa.2020.101642.

51 On the complexity of the bail-in tool, see Tröger (n 44).

52 BRRD, art 63(1); Impact Assessment, 122.

53 Proposal for the BRRD, 12. 
must not be subject to any prior approvals or consents from any person or shareholders, except if a member state has decided to apply ex-ante judicial approval or pre-approval by competent ministry for decisions with direct fiscal impact, nor subject to even any procedural requirements to notify any person or publish any notice. This results in another layer of complexity standing in the way of the managers' fulfilment of their expected obligation to challenge unlawful application of the resolution powers.

Although the high-level view of applying the resolution tools may not, per se, reveal a meaningful negative impact on the interest in appealing, specific powers of the resolution authority under the BRRD may still entail such an intrinsic threat. Article 63(1)(a) provides for the resolution authority's power to demand information; Articles 63(1)(c) and (d) reiterate the right to transfer ownership of shares, other instruments, rights, assets, and liabilities; Articles 63(1)(e) to (k) address more specific powers encompassed by the bailin tool; and Article 63(1)(m) articulates the right to require the competent authority to assess the buyer of a qualifying holding in a timely manner with exceptions to timelines set in the prudential requirements of CRD IV and MiFID II ${ }^{*} 54$. In the main, the naming of the powers of the resolution authorities repeats the resolution tools' description, albeit in more detail, or otherwise does not bring in any meaningful direct conflicts of interest connected with challenging the adoption of such powers.

However, Article 63(1)(b) of the BRRD stipulates a key power for the resolution authorities - that of taking control of an institution and exercising all the rights and powers conferred upon the shareholders, the other owners, and the management body of the institution under resolution. It is obvious that a resolution authority when acting in the stead of the management body of a credit institution would never appeal against its own acts. Moreover, such a broad power could permit withdrawal of any appeals that former or remaining managers have set in motion or might initiate, thereby resulting in complete breakdown of defending the bank's rights via the mechanism of management actions.

Another prominently specified power is set out in Article 63(1)(l) of the BRRD: according to which the resolution authority may remove or replace the management body and senior management of an institution under resolution. In the previous subchapter, addressing the competent authority's power to require the removal of the senior managers or the entire management body, it is proposed that Estonian legislation could include a fundamental deviation from the core principle of recovery framework by giving the competent authority power to directly remove managers. As Article 63(1)(l) of the BRRD grants a similar right of directly removing some or all of the managers to the resolution authority, it is identical in outcome. Should this action be performed unlawfully, the conventional defence of the bank by managers is inadequate in a situation wherein the unlawful act removes the very managers who should exercise their - now removed powers to challenge that act. Even if not all managers are removed, the situation may have a highly negative impact on the remaining managers' motivation to appeal any acts removing other managers.

\subsection{Special management}

Article 35 of the BRRD gives resolution authorities the power to appoint a special manager to replace the management body of the institution. The special manager may have almost total power over the institution: per Article 35(2) of the BRRD, the special manager shall have all the powers of the shareholders and the management body of the institution; however, the special manager may only exercise such powers under the control of the resolution authority. When comparing this mechanism to the temporary administrator addressed in Article 29 of the BRRD, where following the shareholder decisions and company law is generally expected, Article 35(3) states specifically that for special management, promoting resolution objectives overrides any other duty of management in accordance with the statutes of the institution or national law, insofar as they are inconsistent.

According to Article 35(4) of the BRRD, resolution authorities may set limits to the action of a special manager or require that certain acts of the special manager be subject to the resolution authority's prior consent, and resolution authorities may remove the special manager at any time. Just as with the temporary administrators covered in the previous chapter, it is evident that the person(s) consenting to act as special manager have a specific interest in not contesting being appointed to said position and replacing the management board, even if such an act might be unlawful. Moreover, since - as is quite evident - the resolution

54 Directive 2014/65/EU of the European Parliament and of the Council of 15 May 2014 on markets in financial instruments [2014] OJ L173/349. 
authority can limit the special manager's powers or require consent therefrom, the resolution authority may gain full control over the credit institution's decisions, including decisions on appealing against acts by a resolution authority.

\subsection{Persons exercising resolution powers}

While it is stressed that resolution authorities should be able to exercise control over the institution under resolution so as to operate the institution and handle its activities and services with all the powers of its shareholders and management body, the same Article 72(1) of the BRRD creates the possibility of the control being exercised either directly by the resolution authority or indirectly by one or more persons appointed by the resolution authority. This provision, which gives resolution authorities the option to appoint a third party acting on their behalf, differs from the temporary administration covered in chapter 2 of the article and from the special manager addressed by subchapter 3.3 in that it provides for an option of appointing a person to exercise the resolution powers as such, which is fundamentally different from managing a credit institution through the recovery or resolution. However, as the person appointed will have all the powers of the institution's shareholders and management bodies and has a clear interest in not contesting an act that results in his or her appointment, the target institution's ability to appeal against appointment of such a person is, ultimately, similarly hampered.

Lastly, with the above-referenced Article 51(2) of the BRRD reiterates the right to name a person, in accordance with Article 72(1) with the specific objective of drawing up and implementing a business reorganisation plan. Resolution authorities have this power in any case under the general rule of the latter section of the BRRD, and it seems not to grant any extra rights to the resolution authority. Therefore, such an article of law itself seems redundant, as do specific referrals to it as a separate power of the resolution authority. Even if treated as a standalone power, it entails exactly the same implications for appealing against the application of such power as the measure discussed above of naming a person to exercise the resolution powers.

\section{Conclusion}

Bank recovery is based on the fundamental principle of leaving the bank in control. While in recovery the control may be relinquished to the recovery authority, the credit institution as a legal person with its own interests remains in existence. This should also reserve to it the possibility of freely deciding whether to fight back against unlawful application of recovery and resolution actions. This possibility does exist with regard to most of the recovery and resolution measures provided for, which may have only some limited impact in terms of managers' conflicts of interest. However, in some of the cases of recovery and resolution examined, the legal logic in which the credit institution is a person free to decide via its management whether to protect its interests breaks down. The resolution measure of appointing temporary administrators has a profound effect on the bank's ability to challenge such a measure, should it be unlawful, as clearly neither the temporary administrators appointed nor the competent authorities have an interest in challenging said competent authority's act of taking this measure so long as they maintain full control over the credit institution's actions. The resulting effects from the key resolution measures are even more profound, with a similar outcome in the domain of conflicts of interest. While the application of resolution tools may not entail conflicts of interest and create impediments to appealing against application of the tools per se, at least two of the general resolution powers can be unlawfully applied in such a manner that, in consequence of those powers' application, the possibility of the addressee bank challenging such application is, in essence, dissolved. Likewise, the resolution measure of appointment of a special manager has the effect of, to any practical extent, removing the addressee's ability to appeal effectively against such an appointment, as does the appointment of persons exercising resolution powers. It can be concluded that, in several cases, the express right to appeal declared for the credit institutions as the addressees of resolution or recovery measures is fictitious. 